\title{
El nuevo Prometeo. Algunas reflexiones en torno al liderazgo carismático en el contexto de las democracias modernas
}

\section{Gastón Souroujon}

Gastón Souroujon es docente en la Facultad de Ciencia Política y Relaciones Internacionales de la Universidad Nacional de Rosario y Becario CONICET. E-mail: gsouroujon@hotmail.com

\section{resumen}

El presente trabajo intenta rastrear en el pensamiento de los intelectuales más destacados de fines del siglo XIX y principios del XX la concepción de democracia, y particularmente cómo entendían la relación entre líder-masa que con la expansión del sufragio universal se gestaba. En este orden nos detenemos especialmente en la figura del líder carismático, figura ausente en la tradición liberal y su concepción de sujetos autónomos, que se erige sobre las bases del ideal de la autenticidad del romanticismo. A partir de esto analizamos la nueva temporalidad dentro de la teoría política que presentan las democracias con liderazgos carismáticos, la relación de éstos con la burocracia, y el fino límite que separa a estas democracias de experiencias autoritarias. De este modo retomamos a Weber para subrayar el difícil pero siempre necesario equilibrio entre racionalidad y carisma que debe regir toda democracia moderna.

palabras clave

carisma / Weber / democracia / elitistas / burocracia

\section{summary}

The present work try to trace in the thought of the intellectuals more important of the end of the XIX century and the beginning of the XX, the democracy's conception, and particularly how they understood the relation between the leader and mass, that just begging with the expansion of the suffrage. We put our eyes specially in the charismatic leader, figure absent in the liberal tradition and his conception of autonomous subject, that raise from the authenticity's ideal of the romanticism. With these tools we analyze the new conception of time inside the political theory that present the democracy with charismatic leader, the relation between this leader and the bureaucracy, and narrow limits that separate this democracy the authority's experience. We return to Weber to underline the hard but always necessary balance between charisma and rationality that have to lead the modern democracy. keywords

charisma / Weber / democracy / elitist / bureaucracy 
En la historia del pensamiento occidental ha habido periodos en los que todo el universo de significaciones pareciera desmoronarse, en los que el andamiaje conceptual y los supuestos que hasta entonces permitían comprender la realidad se erosionan. Momentos en los que, como afirmaría Marx, todo lo sólido se desvanece en el aire, y el paradigma hasta entonces vigente ni siquiera puede contemplar todas las nuevas preguntas que se debiesen formular. Como sugiere Marshal Berman, los pensadores que habitan estos ciclos padecen la angustia de residir en dos mundos distintos, y de alguna manera sus esfuerzos por interpretar el nuevo ordenamiento social está atravesado por la nostalgia por el edén perdido (Berman, 1989).

La época que se abre a fines del siglo XIX hasta la entreguerra, fue uno de esos umbrales históricos que obligó a los intelectuales a adaptar sus herramientas a la nueva matriz social y política que se estaba gestando, en un contexto en el que sus certezas desaparecían, ante una “...sensación de una destrucción inminente de viejas costumbres e instituciones sociales que ya no se adecuaban a la realidad social" (Hughes, 1972: 11). La aparición de las masas en el espacio público, no sólo trastocó el equilibrio liberal entre espacio público y privado, sino que también introdujo aquellos viejos ídolos que el iluminismo había relegado al ostracismo, comenzando a develar el otro rostro de la modernidad.

Con la introducción del sufragio universal la democracia es rescatada como una forma de gobierno deseable, luego que por siglos la tradición del discurso político la haya relegado por ser un régimen defectuoso, perverso, o a lo sumo imposible. ${ }^{1}$ Atenas sigue siendo el imaginario al que se recurre para pensar la democracia, por eso se la concibe como una forma de autogobierno en donde se fusiona nuevamente ejercicio y titularidad del poder. Sin embargo los sueños de una comunidad autogobernada que en el seno del Ágora forja su futuro, choca contra la realidad del número. El retorno de la democracia como forma de gobierno en un contexto de sociedad de masa transforma las instituciones y valores, y desnuda los elementos no racionales del comportamiento humano y su importancia para la vida social; quedando encerrada en una serie de aporías que invalidan su potencial emancipador, convirtiéndose en una creencia más, en un mito como sugerirá Michels (1983), cuya función es legitimar las relaciones de poder.

Frente a este cambio paradigmático los intelectuales más lucidos de la época, desde diferentes disciplinas, vislumbran los contornos de un nuevo sujeto, de la nueva figura que signará el siglo XX, el líder carismático, el demagogo. Ante la impersonalidad que impone la burocracia y la irracionalidad de las masas, estos nuevos mesías llaman la atención no sólo de Weber, sino también de Le Bon, Freud y Michels, entre otros, quienes depositan en él su confianza para resguardar los espacios de libertad, cohesionar a las muchedumbres y restituir el tiempo político. Como si ante la desaparición del sujeto autónomo liberal que con su razón guiase el camino de la sociedad, la única esperanza que subsiste es un superhombre, ya no caracterizado por su autonomía sino por su autenticidad, y cuya voluntad de poder y magnetismo remplazará la argumentación racional. No obstante que estos autores entrevieron las vetas siniestras que un individuo de tales 
características podía portar (vetas que se desarrollarán en todo su esplendor lustros después) quisieron encontrar en él el núcleo distintivo que desenrollaría todas las paradojas democráticas.

Para bien y para mal sus análisis no estuvieron equivocados; como hemos insinuado el siglo XX, el siglo de la democracia, bien puede ser leído a través de sus grandes guías políticos, un siglo que no sin un dejo de ironía al fin responderá al milenario pedido del pueblo judío plagando de mesías las naciones.

En este artículo procuraremos pensar la relación que se establece entre democracia moderna y carisma a través de la lupa de los autores de la época. Teniendo en cuenta que el fenómeno del carisma, según lo entienden sus teóricos más notables, trasciende las fronteras de los regímenes políticos y las etapas históricas, nos preguntamos qué características específicas se generan a partir de la articulación de este tipo de liderazgo con la democracia moderna, y que consecuencias podemos extraer con el fin de problematizar nuestros propios regímenes. Consideramos que la aparición de estas figuras son ineludibles en el escenario que se inaugura a inicios del siglo XX, pues allende las puertas autoritarias que el carisma abre, también en éste se encuentra la llave para superar algunas tensiones propias de estos procesos.

\section{Sujeto liberal y masas democráticas}

“... ya no saben lo que es la cultura en su más elevado sentido, ni el esfuerzo personal, ni la responsabilidad individual. Por el contrario encuentran su satisfacción en los colectivos, en el grupo" (Thomas Mann, "Advertencia a Europa").

Observamos que el concepto de carisma de Weber puede ser entendido como una profundización del concepto de prestigio que ya Le Bon y Freud habían pensado. Ambas ideas coinciden en que es una condición extraordinaria accesible a pocos, que requiere de los otros para su reconocimiento (imposible pensar el prestigio en soledad) y que penetra en el corazón de los dominados produciendo en ellos un cambio radical. Pero a pesar de que Le Bon también la ve como una fuerza irracional y acude a ejemplos de la religión para visualizarla claramente, es Weber quien al tomar como modelo la figura del profeta explota todas las potencialidades del concepto. En tanto el arquetipo seguido por Freud para calificar al líder es la del padre, que permite a las masas regresar a la niñez, constituyéndose éste como el manto externo de represión y el artífice del lazo que liga a sus hijos por medio del amor y del temor: "Para Freud el líder es pues la encarnación de la experiencia infantil del temido padre primario, a quien cree sobrehumano, rebosante de energía sexual y dotado de poder absoluto... superyó externo de los miembros de la multitud, liberando a los seguidores de la espantosa responsabilidad de autorregulación al brindarle una voz autoritaria y severa que deben obedecer" (Lindholm, 1997: 82); Weber recurre a la imagen del profeta y deposita en él la solución a las pérdidas que la democracia de masa trae aparejada, pérdidas que se pueden ilustrar, tal como lo sugiere Habermas (1989), con dos de sus metáforas, la jaula de hierro o pérdida de la libertad y el cofre vacío o pérdida de sentido. 
A modo de resumen de las consideraciones que Weber realiza en su Sociología de la religión, el profeta es aquel que anuncia una doctrina religiosa o mandato divino, intentando articular una concepción unitaria del universo. Es una fuerza disruptiva con el pasado que entroniza un nuevo sistema de creencias, por eso en muchos casos se transforma en legislador, ya que a pesar de poseer un anclaje irracional, permite racionalizar el comportamiento. Contrariamente al sacerdote, usurpa el poder, reivindicando su autoridad no por la tradición, sino por el carisma que es entendido como una gracia de Dios; aparece en momentos de crisis en territorios en peligro, con una predicación emocional que lo separa del filósofo y lo acerca al demagogo. En caso de que su profecía tenga éxito en la consecución de adeptos, con el tiempo tiende a rutinizarse permitiendo el establecimiento de una congregación permanente que trasciende al profeta y asegura la predicación (Weber, 1997).

El problema de este arquetipo religioso, que se traduce en pensar en un tópico constante en la historia, es cómo articular la naturaleza del carisma con la nueva gramática que inaugura la democracia de masa, qué modulación reviste esta figura que irrumpe en toda la historia política en tiempos de sufragio universal.

Pocos años después que la muerte de Dios fue anunciada, sus asesinos comienzan a ser amenazados; el sujeto autónomo kantiano, espíritu del ciudadano liberal, que sale de la minoría de edad para moldear sus propias leyes con la sola ayuda de su razón sin la necesidad de tutores que lo guíen, comienza a agonizar. Éste, recordemos, se caracterizaba por ser un sujeto responsable de su accionar que había logrado sacarse las ataduras de la superstición y de los mitos ${ }^{2}$; y que a su vez, sobre todo a partir de Descartes, comenzaría un proceso de desvinculación de su propio yo, acallando sus sentimientos, emociones, etc. ${ }^{3}$ constituyéndose en un sujeto puramente racional que impregnaría a la vida pública de predecibilidad y llevaría a la sociedad hacia el progreso indefinido predicado por el iluminismo.

La tradición liberal construyó todo sus supuestos a partir de este individuo autónomo, quien dejaba sus particularidades disruptivas en el mundo privado para hacer de la esfera política el reino de la razón. De alguna manera las dos barreras, utilizadas por los distintos países europeos, para limitar la participación en el espacio político (instrucción y propiedad) respondían a este postulado; por una parte la confianza en que la educación era el medio que elevaría a todos los individuos al grado de madurez necesario, y por otra que la posesión de una propiedad se conectaba con la propiedad de si mismo (siguiendo una lectura lockeana) permitiendo así la independencia con respecto a terceros. Como nos recuerdan autores como Mouffe (2002) y Walzer (2004), el objetivo final del liberalismo político era erradicar las pasiones de la arena política, para lo cual estos autores coinciden en que esta tradición presentó dos modulaciones, la primera centrada alrededor de una razón normativa y la segunda alrededor del interés. La razón y el interés serían entonces los factores que motivan el accionar de los individuos en la arena política, partiendo de una concepción dicotómica entre razón y pasión, en donde la única posibilidad de constituir un orden político estable y armonioso era relegando la segunda y haciendo reinar la primera. 
La autonomía liberal, en un ámbito de pleno respeto de las libertades civiles, iba a permitir que la verdad aflorara a través de la exposición de argumentos racionales. Como apunta Schmitt: "La discusión significa un intercambio de opiniones; está determinada por el objetivo de convencer al adversario, con argumentos racionales, de lo verdadero y lo correcto, o bien dejarse convencer por lo verdadero y lo correcto" (Schmitt, 1990: 8). Es por eso que la institución paradigmática del liberalismo es el parlamento, recinto donde los sujetos provistos sólo de su palabra constituyen a la discusión en un ritual cuyo único interés es la búsqueda de la verdad y la huida del dogmatismo, de ahí que deba existir siempre la posibilidad latente de convencer. No es simplemente hablar para el coro, sino demostrar una mayor coherencia interna en los argumentos, junto con una mayor correspondencia con la realidad, para que así, siguiendo a Schmitt, una postura pueda participar con éxito en la libre competencia de las opiniones.

Si para el liberalismo, dadas ciertas condiciones, todos compartimos la misma posibilidad de hacer uso de la razón, y darnos nuestras propias leyes más allá que difiramos en nuestros intereses privados; para los pensadores que sientan las bases de la psicología estas cualidades pueden hallarse sólo en el individuo aislado, cuya característica privativa es su accionar consciente, conciencia en donde según Le Bon está depositada la capacidad de distinguirnos, de ser únicos. Esta esfera del sujeto, al igual que la concepción liberal, es perfectible por la educación y la cultura, fija autónomamente su voluntad y se siente responsable de su accionar cuyo móvil es el interés personal. Freud amplía esta postura mostrando como este individuo consciente es producto de la represión de los elementos inconscientes por parte de la civilización, que impiden emerger los aterradores instintos que habitan en nosotros " . .. lo inconsciente individual, sistema en el que se halla contenido en germen todo lo malo existente en el alma humana" (Freud, 1984: 13).

Con la inclusión de este elemento inconsciente, Le Bon y Freud introducen la oscuridad, traduciendo lo que era el espíritu intelectual del periodo, que percibía a la concepción del sujeto liberal al menos limitada, ya que se advertía que parte del actuar de los hombres no era reducible a la razón; otros elementos entran en juego, mucho más difíciles de dilucidar, elementos que el iluminismo quiso ocultar bajo el pretexto de la ignorancia. Sin embargo, al introducirse las masas al espacio público las creencias, los mitos, los comportamientos no racionales comienzan a aflorar; el inconsciente, aquello que Le Bon veía que asemejaba a todos los individuos, sale a la superficie obligando a un cambio de cosmovisión.

Si bien Le Bon acepta que la muchedumbre siempre ha cumplido algún rol en el devenir histórico, la era que se está inaugurando se caracteriza porque su presencia es permanente. Afirma el autor: "La edad en que entramos será realmente la era de la muchedumbre" (Le Bon, 1958: 17). También Canetti (cuya obra Masa y poder si bien se edita en 1960 comienza a ser escrita en 1925) coincide en esta apreciación considerando que es la modernidad, con su edificación de grandes ciudades y su incremento de la población, el escenario propicio para que las masas se constituyan (Canetti, 2005: 77). Y es justamente en el actuar de las masas donde los autores perciben estas cualidades psicológicas tan disímiles a las del sujeto liberal. 
El individuo moderno que se había desanclado de las creencias externas y de las emociones internas se desvanece en el seno de las masas, donde vuelve a reinar un comportamiento heterónomo.

Las masas lejos están de conjugarse con una clase social específica, o con un mero accionar delictivo. Se las debe entender como un comportamiento no racional, impulsivo, que hace descender a sus componentes hacia una instancia similar a los primitivos. Presentan un comportamiento maniqueo y simplista que las impulsa siempre a los extremos, y a una supresión de los intereses particulares; es por eso que a pesar de ser inferiores intelectualmente al hombre solitario, en algunas ocasiones se elevan moralmente llegando incluso al autosacrificio. Le Bon define esto con claridad: "Si el desinterés, la resignación, el sacrificio absoluto a un ideal quimérico o real son virtudes morales, puede decirse que las muchedumbres poseen comúnmente estas virtudes... Ellas las practican sin duda con inconsciencia” (Le Bon, 1958: 64).

La diversidad de los individuos que integran las masas se borra, asumiendo éstas cualidades distintas de sus componentes, siendo este nuevo actor otra cosa distinta a la suma de sus partes. Pareciera, según las afirmaciones de Le Bon y Canetti, que existe un ansia del individuo por desprenderse de su subjetividad para incorporarse a ésta, una atracción del sujeto hacia la masa. Según Le Bon lo que se expresa aquí es una exteriorización del inconsciente colectivo, por la falta de freno que permite el anonimato, y a su vez Freud lo comprenderá como la eliminación de las represiones; también en Canetti se halla una argumentación similar ya que la masa permite superar la reticencia al contacto propia del individuo aislado: "Se siente aislado, ya que todas las distancias que lo hacían replegarse y lo encerraban en sí mismo quedan suprimidas" (Canetti, 2005: 76). La consecuencia de este supuesto es que el nivel intelectual de sus componentes no lo hace inmune a este tipo de accionar, ya que al entrar en las muchedumbres la estructura inconsciente común en todos queda liberada.

A partir de lo dicho, pensadores como Michels, Mosca y Pareto pudieron comprender que el ámbito de la política está construido sobre una estructura religiosa, ya que son las creencias y no la razón las que movilizan a este nuevo actor y constituyen el principio de legitimidad; hasta la misma idea de democracia no puede ser deducible de la razón, siendo una creencia más, fenómenos que generan que la práctica política varíe inevitablemente. Tal como afirma Yannuzzi, “... se descubre la política como un tipo de práctica que se asienta sobre un sustrato no racional en el que se desenvuelven las creencias y mitos modernos" (Yannuzzi, 2007: 55).

Un elemento a tener en cuenta es que la palabra sigue siendo el instrumento principal de la política, aunque sufre una metamorfosis en sus intenciones: donde antes se la utilizaba en pos de construir un argumento lógico que convenza a los pares, ahora, como afirma Le Bon, se la usa para evocar imágenes que puedan despertar los sentimientos del rebaño; ya no se apela al entendimiento, sino a este reducto inconsciente al que se pretende encantar, sugestionándola con palabras más que con razones. Es por eso que Michels afirma que las masas son más fáciles de dominar que los grupos pequeños. Según sus propias palabras, "la adhesión de 
la multitud es tumultuosa, repentina e incondicional... La multitud pesa mucho menos deliberadamente las palabras y las acciones que las personas, o grupos pequeños que componen aquella multitud" (Michels, 1983: 72).

La multitud reunida se deja llevar por el contagio grupal y el éxtasis que el orador provoca, suprimiendo su capacidad crítica para discernir entre realidad y fantasía. Es una técnica opuesta al uso de la palabra en el liberalismo, como aduce Adorno, ya que aquí encontrábamos una lógica discursiva que relacionaba premisas e inferencias, en tanto que en la nueva era el discurso es una trayectoria de ideas cuya concatenación se basa en la semejanza, mediante asociaciones que hacen jugar las homonimias, lo que permite a la multitud seguir sin esfuerzo el hilo discursivo "y nada en la corriente de las palabras" (Adorno, 2003: 12). Sin embargo, el autor considera (al menos en Ensayos sobre la propaganda fascista) que esto es típico de la propaganda fascista y no de la política de masas en general, argumentando que los propósitos de la propaganda fascista son irracionales, y hasta contrarios a los intereses de la mayoría que es tomada como niños, característica que, como hemos visto, concuerda perfectamente con la democracia de masas. En este sentido la lectura del novelista Thomas Mann se mostró más aguda que la de muchos filósofos de la época: "Nuestra época ha llevado a cabo esta paradoja: que una asamblea de masas de pobres de espiritu aplaudan con entusiasmo patológico la destrucción de los derechos del hombre pregonados por alguien por un altavoz" (Mann, 1938: 54).

Lo anterior explica porqué autores como Michels o Le Bon, a pesar de remarcar el carácter impredecible y turbulento de las masas, las observan como apáticas e indiferentes. La aparente contradicción se resuelve al entender que todo su accionar, su belicosidad, su propensión a los extremos, no es autoinstituida, sino que depende de un tercero exterior a la misma que le de vida, de un primer motor que la ponga en movimiento. Salvo Durkheim, quien percibe el polo activo en la creatividad generada por la participación colectiva en rituales, por lo tanto en el interior de la masa, la mayoría de los pensadores de esos años encuentra en la figura del líder el elemento que mantiene ligada a los muchos y les impone su contenido. A raíz de esto podemos decir que son todos deudores de Nietzsche, para quien ante el rebaño de ovejas débiles, sumisas e incapaces de voluntad de poder, aparece el superhombre que autoinstituye sus valores constantemente en un universo carente de Thelos, una figura dionisiaca que al igual que un artista posee una virtud creativa sobre sí mismo, situándose más allá de todo entramado moral por lo que cualquiera de sus actos estaba justificado por su misma grandeza ${ }^{4}$. Como afirma Mirrat, "La voluntad de poder es un elemento móvil, variable, plástico que interpreta, modela, confiere sentido y da valor a las cosas... La verdadera creación, donde se expresa su más alta cualidad artística, es la voluntad de transfigurarse uno mismo, de sobrepasarse eternamente" (Mirrat, 2005:18).

Los autores de este periodo observan cómo a la nula voluntad de las masas, se le contrapone necesariamente el máximo de voluntad del nuevo Cesar; como sugiere Michels es una fuerza de voluntad que elimina las otras voluntades, de esta manera el olvido de sí que se produce en un extremo obliga a una afirmación 
radical de sí en el otro. La eliminación del individuo liberal en el seno de la masa, con la consecuente pérdida de sus atributos, pareciera requerir la aparición de un superhombre, es por eso que, siguiendo a Mommsen (1981), la política de algún modo sigue siendo un asunto de personalidades. Creemos que una de las causas de este hecho se encuentra en que el elemento que imponía el dinamismo en el transcurrir histórico dentro del liberalismo, la capacidad de los sujetos de darse sus propias leyes con la sola ayuda de la razón y de esta forma avanzar hacia un progreso indefinido, desaparece cuando estos sujetos se transforman en masas, cuyas características son estáticas e incapaces por si mismas de salir de un estado de entropía. Es necesario por lo tanto que los nuevos caminos de la historia sean ejecutados desde fuera por personajes distintos a las masas, aunque el nuevo devenir histórico difiera del anterior.

\section{Carisma y autenticidad}

La característica principal que signará a este líder en las democracias modernas ya no será la autonomía sino la autenticidad; ya Weber (2000) había advertido que el hombre con vocación política es el hombre auténtico. Si bien tanto la autonomía como la autenticidad son hijas de la modernidad ${ }^{5}$, en líneas generales podemos decir que recuperan vertientes distintas de ella; en tanto que la autonomía es la hija pródiga del iluminismo, la autenticidad es un producto del romanticismo (aunque podemos rastrear sus antecedentes en Rousseau). Ésta pone el acento no tanto en el actuar siguiendo la razón, sino especialmente en que en el actuar debe reflejar fielmente la más profunda originalidad del individuo, aquello que lo convierte en único, sin suprimir sus instintos y emociones, de manera que cuando el individuo actúa revela su personalidad más que su cualidad de sujeto autónomo.

Desde este plano se puede entender la autorresponsabilidad propia del líder carismático que menciona Mommsen (1981), como la responsabilidad ante las más íntimas convicciones, siendo el yo interior el espacio último al que debo rendir cuenta. El líder de masas debe ser un sujeto auténtico, que en un universo público plagado de impersonalidad y en el que la subjetividad desaparece, posee las fuerzas suficientes para diferenciarse mostrando su especificidad, para exteriorizar sus convicciones internas, su más profunda creencia, e impregnar con ellas a sus seguidores, que, como advertimos anteriormente, se ven hipnotizados no por el relato en si, sino por la fuerza de convicción de su jefe, por la credibilidad que sabe desatar y que no es otra cosa que el despliegue de su autenticidad. En este sentido, “...en el campo especificamente político, la validez de un enunciado nunca se determina por el grado de verdad que contenga, sino por el grado de credibilidad que goce quien lo emite" (Yannuzzi, 1993: 41).

Esta atadura con la persona del líder más que con la realidad empírica, lleva a que las muchedumbres vivan dentro de un mundo ficcional, al que es imposible intentar criticar a partir de razones; quien lo intente se convierte automáticamente en un réprobo, en el otro, quien se ve excluido, y llegado el caso perseguido por la hermandad naciente. Efectivamente esta aptitud para separar ficción de realidad expresa su distinción. Tal como enuncia Arendt (1999), las masas confían 
más en la imaginación que en el mundo sensible. El garante de esta ficción es el mismo líder, él la encarna, la interpreta y llegado el caso sólo él puede develarla correctamente, brindando a sus seguidores una construcción ficticia pero coherente que resuelve su necesidad de certezas, devolviéndoles la esperanza del paraíso religioso. De esta manera la angustia que la erosión de las grandes religiones había provocado, es cicatrizada con la elaboración de estas nuevas religiones laicas (socialismo, democracia).

Sin embargo el hecho de que el futuro prometido se halle en la esfera terrenal, relativiza la separación entre realidad y ficción, apreciación que se puede inferir en la mayoría de los autores (Freud, Le Bon, Weber, Michels), quienes anclan la perdurabilidad de la fascinación que rodea al líder en el éxito que éste pueda llegar a tener en la consecución de las promesas materiales, en la concreción de la profecía. En palabras de Weber, "el héroe carismático no deriva su autoridad... de normas y reglas... Sólo la alcanza y la mantiene por la prueba de sus propias energías en la vida. Si quiere ser un profeta debe hacer un milagro; si quiere ser un caudillo primero, debe realizar acciones heroicas. Pero ante todo debe probar su misión divina por el hecho de que a las personas que a él se consagran y en él creen les va bien" (Weber, 1996: 850).

A pesar del espíritu de la época que impregna a todos estos autores suscitando sus coincidencias, podemos notar una importante diferencia entre los psicólogos, Le Bon y Freud, y los sociólogos como Weber y Pareto. En tanto que los primeros advertían que la relación entre masas y líder se tornaba más perdurable en el caso que el fascinador también esté fascinado; los sociólogos si bien aceptan la necesidad de la autoconvicción del líder rechazando la posibilidad de que éste sea un mero manipulador, le atribuyen una cualidad extra que le permite independizarse relativamente de las creencias. En este sentido, Pareto intuye que el líder debe tener la capacidad de desdoblarse y separar sus convicciones de su razón, para utilizar las primeras instrumentalmente, aunque paradójicamente logra mayor eficacia cuando olvida su intención utilitaria. "La paradoja se presenta cuando se observa que el sujeto instrumentalmente más eficaz es aquel que no se piensa como actor u olvida su intención instrumental... El político debe saber oscilar entre el escepticismo y la fe. Debe ser creyente para persuadir, instrumental para construir poder" (Kitzberger, 2004: 327).

Por su parte, en su discurso "La política como vocación", Weber subraya que dentro de las virtudes del político no sólo se debe encontrar la pasión por una causa sino también la mesura (Weber, 2000). A partir de este argumento, Dow Jr. plantea que existe una transformación en la conceptualización weberiana del carisma en el transcurso de sus distintas obras. Mientras que en Economía y Sociedad se acentuaba el aspecto dionisiaco del carisma, en el discurso anteriormente citado hay una pretensión de Weber de moderar este elemento irracional a partir de la combinación de las dos éticas (la de la convicción y la de la responsabilidad). El propio Dow Jr. lo expresa así: “Thus Weber's whole or genuine man represents a synthesis of charisma and asceticism: He does not have the total freedom of his Dionysian predecessor in the earlier formulation of charisma; yet he is not without 
warmth" (Dow Jr, 1978: 88). La autoconvicción se ve contrarrestada así por una ética de la responsabilidad que la contiene al obligar al político a evaluar las consecuencias de sus actos.

\section{Burocracia y carisma}

La creciente burocratización que acechaba a la organización de los nuevos Estados al tener que ocuparse de funciones cada vez más complejas en un espacio público de mayor alcance, fue un fenómeno que no pasó desapercibido por los intelectuales de la época, pero sería Michels el que va a explotar todas las trágicas paradojas que este proceso escondía. La naciente sociedad de masas, supone la introducción al espacio público de un gran número de personas desorganizadas que encuentran en la organización la única forma de articular su voz al unísono, organización que se ve obligada a igualar cercenando las diferencias; por otro lado, a partir de esta ampliación el espacio público se complejiza, atrayendo a su seno un mayor número de problemas cuya resolución demanda un conocimiento especializado, aumentando el despotismo y la discrecionalidad de aquellos que lo poseen, a la vez que la preeminencia del ejecutivo sobre el parlamento. Como afirma el autor, "La especialización técnica que resulta inevitablemente de toda organización extensa, hace necesario lo que se ha dado en llamar la conducción experta" (Michels, 1983: 72).

Ahora bien según Michels esta consecuencia de la democracia impide el desarrollo de la misma democracia, ya que esta estructura administrativa tiende a suprimir los espacios de libertad e instaura una mediocre igualación que hace descender las capacidades individuales, independizándose de la voluntad de los individuos, generando intereses propios cuyo último fin es el mantenimiento en el poder; por eso en toda la obra de Michels sobrevuela esa idea condenatoria de que toda organización termina siendo devorada por una fuerza conservadora.

El pensador alemán decontruye el mito democrático. El supuesto gobierno de todos se transforma invariablemente en el gobierno de unos pocos cuyos objetivos se emancipan, volviéndose la mayoría de las veces contrarios a la voluntad colectiva. Este el momento en el que la figura del líder juega un papel relevante, ya que al ser el responsable de convocar al número puede lograr una autonomía relativa con relación al Partido, pues su posición es dueña de una legitimidad apoyada en el sufragio. Sin embargo el Michels de Los Partidos Políticos termina teniendo una perspectiva pesimista del líder, ya que éste a fin de cuenta forma parte de la elite, y sus intereses al igual que los de la burocracia están marcados por la conservación del poder; años más tarde, según Lipset (en la introducción a la obra de Michels) encontraría, al igual que Weber, en el líder carismático (en su caso Mussolini) la figura capaz de disolver el conservadurismo que implica la organización.

Es Weber el que hace detonar toda la tensión que subyace entre organización y líder. Esta contradicción de alguna manera recorre toda su obra, desnudando no sólo su pesimismo, sino también la desazón de aquel ser sensible que se sabe testigo de la desaparición del mundo tal como lo conoció. Weber se erige así en el autor paradigmático de este cambio de escenario, y el que logra precisar todas las 
ambivalencias y puertas al vacío que el proceso de racionalización producía. Aquí nos interesa desarrollar cómo funcionan y se contraponen dos de las construcciones tipo ideales de dominación: la racional legal por medio de cuadros burocráticos y la carismática. La primera es consecuencia del proceso de racionalización que afecta a los Estados-nación de occidente, constituyendo el terreno de estabilidad y certezas necesarias para el desarrollo del capitalismo; es una dominación cotidiana, sumamente impersonal que se apoya en la normatividad. Al igual que Michels, Weber advierte la fuerte tendencia que habita en estas sociedades a ser dirigidas por la burocracia ya que demostró ser una forma de organización más eficaz y precisa que cualquiera de sus predecesoras. Sus palabras son elocuentes al respecto: "La razón decisiva que explica el progreso de la organización burocrática ha sido siempre su superioridad técnica sobre cualquier otra organización. Un mecanismo burocrático perfectamente desarrollado actúa con relación a las demás organizaciones de la misma forma que una máquina con delación a los métodos no mecánicos... La precisión, la rapidez, la univocidad... son infinitamente mayores en la administración severamente burocratizada" (Weber, 1997: 731). Como contracara aparece la dominación carismática, extraordinaria y disruptiva, que trastorna el letargo de la sociedad, dotándola nuevamente de sentido a partir de la creencia en el nuevo profeta.

El costo de la preeminencia de la burocracia se expresa en la pérdida de libertad y espontaneidad, en el encierro de la individualidad en jaulas de hierro, ya que uniforma, diluyendo las diferencias en esquemas prefijados, convirtiendo a los individuos en autómatas que reaccionan ante pautas establecidas y son incapaces de obrar espontáneamente. El modelo taylorista de producción es un microcosmo que ilustra bien este esquema, como dice Mommsen “... procesos anónimos de burocratización y rutina que apuntan básicamente a la construcción de envoltura de acero, en una sociedad, en gran medida anquilosada" (Mommsen, 1981:14). La burocracia se erige sobre una sociedad disciplinada, compuesta por súbditos que acatan acríticamente órdenes diseñadas a partir de una razón instrumental (Weber pone el ejemplo del ejército y la empresa). La individualidad termina siendo adiestrada y convertida en un engranaje más de una maquinaria que la excede; nos encontramos, siguiendo a Mommsen, en el mundo del hombre del orden cuyo ideal es la adaptación y la obediencia. Sin embargo este tipo de dominación sólo logra insertarse en el actuar externo de las personas, no en sus motivaciones; al igual que en Hobbes se basa en una coacción externa que no incide en el fuero interior; una transformación del accionar derivada especialmente de los cambios técnicos que obligan a una nueva condición de adaptación.

Vemos que el problema de la libertad en Weber tiene dos facetas que van unidas. En primer lugar la necesidad que la burocracia esté controlada por el parlamento para evitar que aquélla ejerza un dominio autoritario. Pero lo que más nos interesa aquí es resaltar que sólo la aparición del líder carismático puede subvertir este monótono disciplinamiento con la introducción de lo nuevo. La libertad es entendida, entonces, como el elemento de creación, de imprevisibilidad, de ruptura con el enclaustramiento del orden. El líder carismático es el único que puede elevarse por 
encima de la rutina establecida por la burocracia y generar espacios de libertad individual; concepto que posee una connotación existencial ya que florece al afirmar el líder su condición de hombre capaz de decidir sobre su destino. La aparición de este personaje saca a la sociedad del determinismo, abre las puertas de la jaula de hierro, posibilitando la creación de un nuevo orden que, como veremos, volverá a caer luego en las manos de la burocracia.

El proceso de racionalización corre paralelamente al desencantamiento del mundo, a la desaparición de la magia para la explicación del mundo, proceso que llega a su punto máximo con la ética protestante que genera las motivaciones morales que permiten el capitalismo. Sin embargo una vez establecido el capitalismo, la acción instrumental que éste exige entra en contradicción con cualquier doctrina religiosa, con cualquier cosmovisión que permita dotar de sentido a la vida. El núcleo trágico ocurre cuando el reino de la acción racional con arreglo a fines se evidencia incapaz de saciar las dudas existenciales, y por lo tanto de brindar la sensación de seguridad que reinaba siglos atrás. Weber, recuperando a Tolstoi, nos recuerda la falta de sentido que posee la vida y la muerte para el hombre moderno: “...si la muerte constituye o no un fenómeno que tenga sentido. La respuesta que da es que la muerte para el hombre con cultura, no la tiene... Podría sentir el cansancio de vivir mas nunca la saciedad de la existencia... Por lo tanto, para él la muerte está privada de sentido y tampoco lo tiene la cultura en cuanto tal..." (Weber, 2001: 97).

El líder carismático nuevamente parece ser el encargado de restituir el plexo de sentido. Como sugería Le Bon éste instaura las ilusiones, y lo puede hacer especialmente porque su dominio es interno, porque es a partir de las relaciones que entabla con las masas que las transforma desde dentro, al apropiarse éstas de sus ideas; no es sólo un dominio externo como en el caso de la dominación racional legal. Nótese aquí la similitud que posee el líder carismático de Weber con la figura casi mítica del legislador en Rousseau; ambos son seres extraordinarios, fundadores de naciones, que logran cambiar la naturaleza humana, uno mediante los valores que impone a sus seguidores, el otro a través de leyes; en ambos, aunque de manera distinta, este cambio se torna necesario para adentrarse al nuevo tipo de sociedad, en el ginebrino al contrato social, y en Weber a la comunidad que nace con la identificación de las masas con su líder.

Para cerrar este apartado quisiéramos remarcar que si bien el pesimismo de Weber concede que la tendencia a la burocratización tiene un carácter inquebrantable, ya que en las condiciones de una sociedad de masas no se puede pensar una dominación sin esta estructura, el carácter positivo, el sesgo de esperanza lo deposita en aquella figura que recupera del principio de los tiempos, el nuevo profeta. Él es el único que puede contrarrestar los peligros que acechan a la modernidad. Por eso creemos errónea la postura de Lindholm quien afirma que Weber se inclina por la dominación burocrática. “...Weber acepta también la oposición entre el genio y las restricciones civilizadas. Pero... Weber en general toma partido por las restricciones civilizadas, a pesar de creer que éstas... destruyen todo lo que es glorioso, impetuoso y emocionalmente fascinante en el mundo" (Lindholm, 1997: 42). La 
apuesta de Weber por la rutinización antiautoritaria del carisma no es otra cosa que el intento por mantener precisamente un espacio glorioso y emocionalmente fascinante.

\section{Tiempo y carisma}

Quizás una de las rupturas más grandes que observamos en los pensadores de esta generación se inscribe en su concepción del tiempo. Se deja de lado la noción ilustrada que impregnara al marxismo y al positivismo, de una historia con sentido, que abarcase a toda la sociedad y la llevase hacia una dirección irresistible, ya sea que el motor de esta temporalidad sea la razón o la lucha de clases, un proceso lineal o dialéctico. Versiones todas que no son más que una secularización de la teleología judeocristiana, en la que se intenta hallar una finalidad que tiña la marcha de la sociedad, y en la que en el futuro se esconda el significado último de la historia.

Weber explícitamente crítica cualquier tipo de filosofía de la historia, aun así podemos rastrear en su obra una concepción del cambio social, concepción que de alguna manera ya se encontraba en los elitistas. A pesar de las diferencias entre Mosca, Pareto y Michels, en los tres se observa una temporalidad cíclica, que altera estabilidad y cambio, clausura y apertura (Yannuzzi, 1993: 87). El tiempo, en estos autores, está estigmatizado por la vida de las elites, su aparición, estabilización en el poder y decadencia (si bien podemos notar diferencias significantes en la radicalidad del proceso), el devenir social respira el ritmo que le infunda la suerte de las elites. La apertura se da con la aparición de una nueva elite, lo que no supone un progreso, sino, según Pareto (1987), un nuevo cambio de forma, forma que incide en la elección de la nueva elite (también Mosca observa que un cambio en la fórmula política conlleva un cambio en la clase política). Este cambio de forma, que por ejemplo lleva a una clase política de intelectuales reemplazar una de guerreros, opera sobre un fondo inalterable de lenta y perpetua circulación "Este fenómeno de las nuevas elites, que, por medio de un movimiento incesante de circulación, surgen en las capas inferiores de la sociedad, ascienden a las capas superiores, se desarrollan allí y, después entran en decadencia, son aniquiladas y desaparecen..." (Pareto, 1987: 75).

Una posible lectura de Weber nos conduce a conclusiones contrarias a esta percepción cíclica, sugiriendo que a pesar de su propio rechazo podemos rastrear en él una filosofía de la historia, una teleología negativa, que paradójicamente infiere que el sentido de la historia es la progresiva pérdida de sentido y libertad, tras el continuo proceso de racionalización. Autores como Lindholm (1997), que ven en Weber una trágica postura evolutiva que va de los líderes carismáticos a la burocracia racionalizada, o Hawthorn (2002) para quien Weber cae en la trampa de la historia al atribuir estatuto de necesidad histórica a todos los elementos que hicieron posible el capitalismo, representan esta perspectiva, como nos sugiere la siguiente cita: “... no pudo escapar totalmente de su propio precepto de no atribuir sentido a la historia... su compromiso con lo que para él era la regularidad y la universalidad del capitalismo occidental lo llevó a imputar sentido al futuro de los acontecimientos pasados..." (Hawthorn, 2002: 146). 
Mommsen (1981) ofrece otra interpretación más rica y compleja, partiendo de una lectura de los tipos ideales de dominación como formas extremas que se combinan de distintas maneras; se puede concebir la historia como un modelo dualista de cambio, en donde se intercalan la perpetua tendencia a la rutinización y el disciplinamiento propio de la dominación burocrática, deteniéndose el tiempo en un eterno presente sin vestigios de novedad, y la aparición en momentos de crisis del elemento carismático que produce el acontecimiento único, revolucionario, provocando un nuevo ciclo en el arco temporal debido a la implementación de nuevos valores. A su vez esta naciente orientación con el tiempo sufrirá una nueva racionalización, empujada especialmente por los intereses materiales “... toda capacidad fuera de lo común hace brotar una creencia carismática que luego vuelve a disolverse en lo cotidiano” (Weber, 1996: 867). En este orden la historia puede ser leída como la lucha entre dos fuerzas que se superponen constantemente; la extraordinaria que genera la apertura, y la ordinaria que recupera esta creación y la rutiniza, una fuerza vertiginosa que luego es clausurada por la fuerza de la inercia.

En todo principio siempre está el gran individuo; es él, no el pueblo, el que mediante un acto fundacional dota de sentido a la historia (sentido siempre transitorio). Podemos apreciar así en el líder carismático un aire familiar al héroe romántico de Carlyle (1985) que moldea la historia universal, dejando al pueblo el papel secundario de reconocerlo. Es inconcebible entender lo nuevo desde otra forma de dominación; en la tradicional y en la racional legal siempre encontramos un eterno control de las normas, lo nuevo debe ser introducido desde fuera por una fuerza capaz de emanciparse de la realidad y cubrirla con sus propios valores. Sus irrupciones son invariablemente disruptivas con la cosmovisión reinante, por eso su figura es siempre herética, criticada y rechazada por los intereses creados. $\mathrm{Su}$ aparición al igual que en Schmitt, al igual que la profecía judía, se da en un contexto de crisis que deja a las masas disponibles a la absorción de una nueva motivación; se da cuando la dominación ordinaria no halla dentro de su estructura respuestas para esta situación y se impone la necesidad de una redisposición de valores que permita sentar las bases de un nuevo periodo de normalidad.

Vale aclarar que cuando hablamos de la novedad, de la revolución o apertura de la historia que trae consigo el líder carismático, nos referimos específicamente al carácter de ruptura con el orden dado, lo que no excluye la posibilidad de que el cambio se modele como una vuelta a creencias anteriores tenidas por superadas. Los estallidos religiosos en el seno de sociedades secularizadas son un buen ejemplo. Lo que une a las distintas manifestaciones carismáticas es su capacidad para dotar sentido nuevamente y liberar a los sujetos de la jaula de hierro que conlleva la dominación legal racional.

Vemos entonces que el dibujo cíclico que proponían los elitistas no se distancia mucho de esta historia en desnivel que sugiere Mommsen. En ambas interpretaciones descubrimos momentos de estabilización y momentos de rupturas que permiten nuevas estabilizaciones. Ambas se conciben como tendencias que se repiten desde los albores de la historia, y no conducen a una dirección predeterminada. La 
diferencia está no sólo en la importancia que Weber le atribuye al líder carismático como forjador de orígenes (lo que también podemos rastrear en la afirmación de Mosca de que las individualidades enérgicas y con prestigio son las que se hallan en los inicios de las autocracias), sino sobre todo, en su temor ante los peligros que esconden los tiempos normales.

\section{Democracia y carisma}

Schmitt (1990) advirtió que si bien había una contraposición entre democracia y liberalismo, democracia y dictadura muchas veces conviven en un mismo régimen. La democracia en sociedades de masas mantiene latente elementos autoritarios, paradoja que encuentra en la figura del líder carismático uno de sus nudos explicativos. Weber indica que en su origen el carisma es autoritario; ante la gracia divina con que se rodea a estos personajes es imposible la divergencia, construyen un universo cerrado que requiere la sumisión total a él o la exclusión. Ahora bien, esta cualidad en las sociedades de masa ya no apela directamente al mandato divino para constituir su autoridad, sino que se reestructura en el plebiscito, que le permite al elegido erigirse como encarnación de la voluntad general, como la personificación del espíritu del pueblo ${ }^{7}$, por lo que aquel que se oponga a sus decisiones se convierte en el enemigo del pueblo. Desaparecen así las mediaciones entre Estado y sociedad, produciéndose una relación de identificación entre el líder y las masas "... aun en el caso en que se trate de un sistema basado en la división de poderes, ésta queda anulada en los hechos debido a que la relación de legitimación se establece directamente con el líder sin reconocer instancias intermedias" (Yannuzzi, 1998).

El plebiscito no debe comprenderse como una forma de votación en la que las voluntades individuales exponen sus preferencias, sino como una manifestación de reconocimiento ante las cualidades del líder; éste por lo tanto, más que un producto de las masas es quien las forja, quien las homogeniza, mediante su arsenal de elementos carismáticos (demagogia, emotividad...). Este mecanismo es un mero ritual donde se escenifica esta relación con el líder, y se expone numéricamente sus fuerzas frente a sus adversarios. Cumple así una doble función: en el seno interno es una ceremonia, un ritual, que reproduce la fe en el líder por parte de sus adeptos, en el orden externo una demostración de sus fuerzas.

Podemos afirmar, siguiendo a Mosca (2004) que si en la fórmula política anterior lo que justificaba la autoridad es el precepto de Dios, en la nueva fórmula política es el gobierno de todos el que se presenta como principio de legitimidad. Ante la imposibilidad práctica de este principio, el líder plebiscitario recrea la ilusión presentándose como un vasallo de las masas, independizándose luego de cualquier tipo de exigencia, pasando de dominado a dominador, sobrevolando la sociedad a partir de cierta autonomía derivada del hecho de que no debe responder a nadie salvo a él mismo, ya que es quien mejor conoce las verdaderas necesidades de sus electores. Esta desviación abre las puertas para que las prácticas autoritarias se introduzcan en este tipo de sociedades, provocando las experiencias más nefastas de la historia del siglo XX, y de algún modo, empañando también la misma democra- 
cia presidencial, ya que ninguna ingeniería constitucional que permita la elección directa del líder, puede obstruir totalmente la tendencia autoritaria. Mommsen lo expresa con suma claridad: "Cuanto más manifiesto y personal plebiscitario... es el componente carismático de este acto de legitimación, tanto más alejada la posición del político elegido de la de un funcionario elegido, que está obligado con respecto a un elector... sólo está guiado por su responsabilidad frente a un asunto que sostiene con toda su entrega personal" (Mommsem, 1981: 72).

Ante la paradoja que supone que la solución del encierro que representa la burocracia, se encuentra en un líder carismático que puede degenerar al autoritarismo, ante el dilema de la pérdida de la libertad y el obligar a ser libres, Weber encuentra en la democracia plebiscitaria una construcción capaz de navegar entre Escila y Caribdis, no resignándose ante un dominio sin liderazgo pero tampoco radicalizando los elementos autoritarios que aquí se encuentran. La democracia plebiscitaria es una transformación antiautoritaria del carisma, que permite hacer interactuar la legitimidad carismática que ostenta el líder con la racional legal que deviene de la fe en la legalidad del sistema existente (Mommsem, 1981: 72). Al ser el reconocimiento del carisma por parte de los súbditos el fundamento de la legitimidad, posibilita que distintos demagogos puedan competir en el espacio público dentro de un marco de reglas de juego establecidas (principio mayoritario). Es una suerte de combinación de los dos tipos ideales de dominación, que se sustenta en un equilibrio en el que las tendencias perniciosas de cada uno se contrarrestan. Equilibrio por el cual el jefe plebiscitado brinda ese dominio personal, el punto externo que permite escapar del eterno encierro de la administración, y el entramado de reglas, racionaliza el problema de la sucesión, facilitando la alternancia en el poder y limpiando al carisma de algunos de sus elementos irracionales, en especial su elemento antieconómico.

Este equilibrio es el que rige la mayoría de las democracias que residieron en el siglo XX, produciendo un escenario siempre precario arrastrado por las fuerzas que lo integran, fuerzas que no obstante domesticarse mutuamente siguen impregnando a las democracias de ese carácter cíclico y repetitivo. La forma en que estos principios conviven varía de democracia en democracia. Toda experiencia conforma un particular modo de negociación entre estas dos lógicas, sin embargo ninguna puede sobrevivir por largo tiempo sin contemplar a las dos. Los abismos del autoritarismo y de la pérdida de libertad y sentido se erigen como amenaza siempre presente ante esta posibilidad. Los dos extremos llevan a la clausura del espacio público, ya que tienden a monopolizarlo negando la pluralidad, y amenazando constantemente las mismas libertades civiles. El carisma es una problemática que fascina a aquellos que se atreven a acercase, ya que en él se encuentra un foco explicativo, que devela muchos interrogantes de la teoría política que otras perspectivas no alcanzan a vislumbrar; pero a su vez fascina, como fruto prohibido, porque mantiene para aquellos que lo estudian una opacidad, una cara oculta, un núcleo duro que es imposible racionalizar, pero parece prometer el paraíso recobrado. $\left.\left.\int^{m}\right\}^{m} a^{m}\right]^{m}$ 


\section{Referencias}

1. Nótese que el mismo Rousseau, a quien se lo señala como padre de la democracia, reniega explícitamente de ella por ser una experiencia sólo apta para dioses.

2. La frase de Diderot: "Si lo mantengo, la superstición es más injuriosa para Dios que el ateismo... Su Dios no es sino un producto de la imaginación” ilustra bien esta sensibilidad (Diderot, 1984: 31).

3. Ver Taylor (1996).

4. Dostoievski en Crimen y Castigo expondrá una teoría similar por la cual cualquier delito cometido por una gran personalidad se sitúa más allá de cualquier juicio, autovalidándose.

5. Para una mayor exposición de la contraposición entre autonomía y autenticidad ver: A. Ferrara (2002), C. Thiebaut (1998) y Ch. Taylor (1996).

6. Así la visión de Weber del hombre genuino representa una síntesis de carisma y ascesis: él no tiene la libertad total de su predecesor Dionisíaco en la formulación más temprana de carisma; pero no está sin calor.

7. Fenómeno que se expresa lúcidamente en la siguiente cita de Sastre: "Hoy yo camino delante de mi pueblo como su primer soldado... En una hora todo el pueblo alemán se unirá a mí. Sentirá mi voluntad como su voluntad, lo mismo que yo considero su porvenir y su destino como el motor de mis actos" (Sartre, 1995: 121).

\section{Bibliografía}

T. ADORNO (2003) [1970], Ensayos sobre la propaganda fascista, Barcelona, Voces y Cultura.

H. ARENDT (1999) [1951], Los origenes del totalitarismo, Barcelona, Taurus.

M. BERMAN (1989) [1982], Todo lo sólido se desvanece en el aire, Buenos Aires, Siglo XXI.

E. CANETTI (2005) [1960], Masa y poder, Madrid, De Bolsillo.

T. CARLYLE (1985) [1840], Los héroes, Madrid, Sarpe.

D. DIDEROT (1984) [1746], Pensamientos Filosóficos, Madrid, Sarpe.

T. DOW Jr. (1978), “An analysis of Weber's work on Charisma”, disponible en: http://www.jstor.org pss/589221

A. FERRARA (2002), Autenticidad reflexiva, Madrid, Manchado.

S. FREUD (1983) [1921], Psicología de las masas y análisis del yo, Buenos Aires, Santiago Rueda.

J. HABERMAS (1989) [1981], Teoría de la acción comunicativa (tomo I), Buenos Aires, Ed. Taurus.

G. HAWTHORN (2002) [1976], Iluminismo y desesperación, Buenos Aires, Nueva Visión.

S. HUGHES (1972) [1958], Conciencia y sociedad, Madrid, Aguilar.

P. KITZBERGER (2004), "La crisis del orden liberal y el ascenso del fascismo en cuatro artículos de Wilfredo Pareto para La Nación", en Deus Mortales, Buenos Aires, Nro. 3.

G. LE BON, (1958) [1895], Psicología de las multitudes, Buenos Aires, Albatros.

Ch. LINDHOLM (1997) [1990], Carisma, Barcelona, Gedisa.

T. MANN (1938), Advertencia a Europa, Buenos Aires, Sur.

R. MICHELS (1983) [1915], Los Partidos Politicos (Tomos ly ll), Buenos Aires, Amorrortu.

B. MIRRAT (2005) [2000], "Introducción”, en F. NIETZSCHE, La voluntad de poder, Madrid, Edad.

W. MOMMSEN (1981) [1974], Max Weber: Sociedad, politica e historia, Buenos Aires, Alfa.

G. MOSCA (2004) [1896], La clase política, México, Fondo de Cultura Económica.

Ch. MOUFFE (2002), Politics and passions, Londres, CSD.

V. PARETO (1987) [1906], Escritos sociológicos, Buenos Aires, Alianza.

J. P. SARTRE (1995) [1945], El aplazamiento, Buenos Aires, Losada.

C. SCHMITT (1990 [1917], Sobre el parlamentarismo, Madrid, Tecnos.

- (2005) [1922], Teología Política, Buenos Aires, Struhart.

Ch. TAYLOR (1996) [1989], Las fuentes del yo, Madrid, Paidós.

C. THIEBAUT (1998), La Vindicación del Ciudadano, Barcelona, Paidós.

M. WALZER (2004) [1999] Razón, política y pasión, Madrid, Visor.

M. WEBER (1996) [1922], Economía y sociedad, México, Fondo de Cultura Económica.

(1997) [1921], Sociología de la religión, Madrid, Istmo.

(2000) [1910], El político y el cientifico, México, Coyoacán. 
M. YANNUZZI (1993), Intelectuales, masas y elites, Rosario, UNR Editora.

(1998), "La categoría de Cesarismo en los Inicios de las Sociedad de Masas", disponible en: http://168.96.200.17/ar/libros/yannuzzi.rtt

(2007), Democracia y sociedad de masa, Rosario, HomoSapiens Ediciones.

Recibido: 17/03/2009. Aceptado: 30/09/2009. 